\title{
Phần mềm Việt bayesvl chính thức xuất bản trên CRAN
}

30/05/2019 6:39 SA

Ngày 24/05/2019, chương trình máy tính "bayesvl” chạy trên môi trường R (ngôn ngữ lậf cho tính toán thống kê và đồ họa) do Trung tâm Nghiên cứu Khoa học Xã hội liên ngành (I triển chính thức được xuất bản trên CRAN - thư viện lưu trữ, phân phối các phiên bản cl dấu cột mốc quan trọng cho hành trình hơn 18 tháng lên ý tưởng, thiết kế và triển khai $c$ CRAN.)

Từ cuối năm 2017, Trung tâm ISR đã bắt đầu nghiên cứu khả năng ứng dụng thống kê truyền thống cho Khoa học xã hội và nhân văn (KHXHNV). Bayesian là một cách tiếp cận sử dụng phần mềm này rộng rãi vẫn còn gặp nhiều khó khăn do sự phức tạp của các yế góp phần cải tiến phương pháp khoa học, đồng thời hướng tới xu hướng Open Science cứu, Trung tâm ISR đã xây dựng chương máy tính 'bayesvl' trên môi trường R. Phần mền phạm, hỗ trợ người tiếp cận và sử dụng thống kê Bayesian thông qua xây dựng, thiết kế phỏng $\mathrm{MCMC}$, thực hiện kiểm tra thông số kĩ thuật và kết quả bằng hình ảnh. 

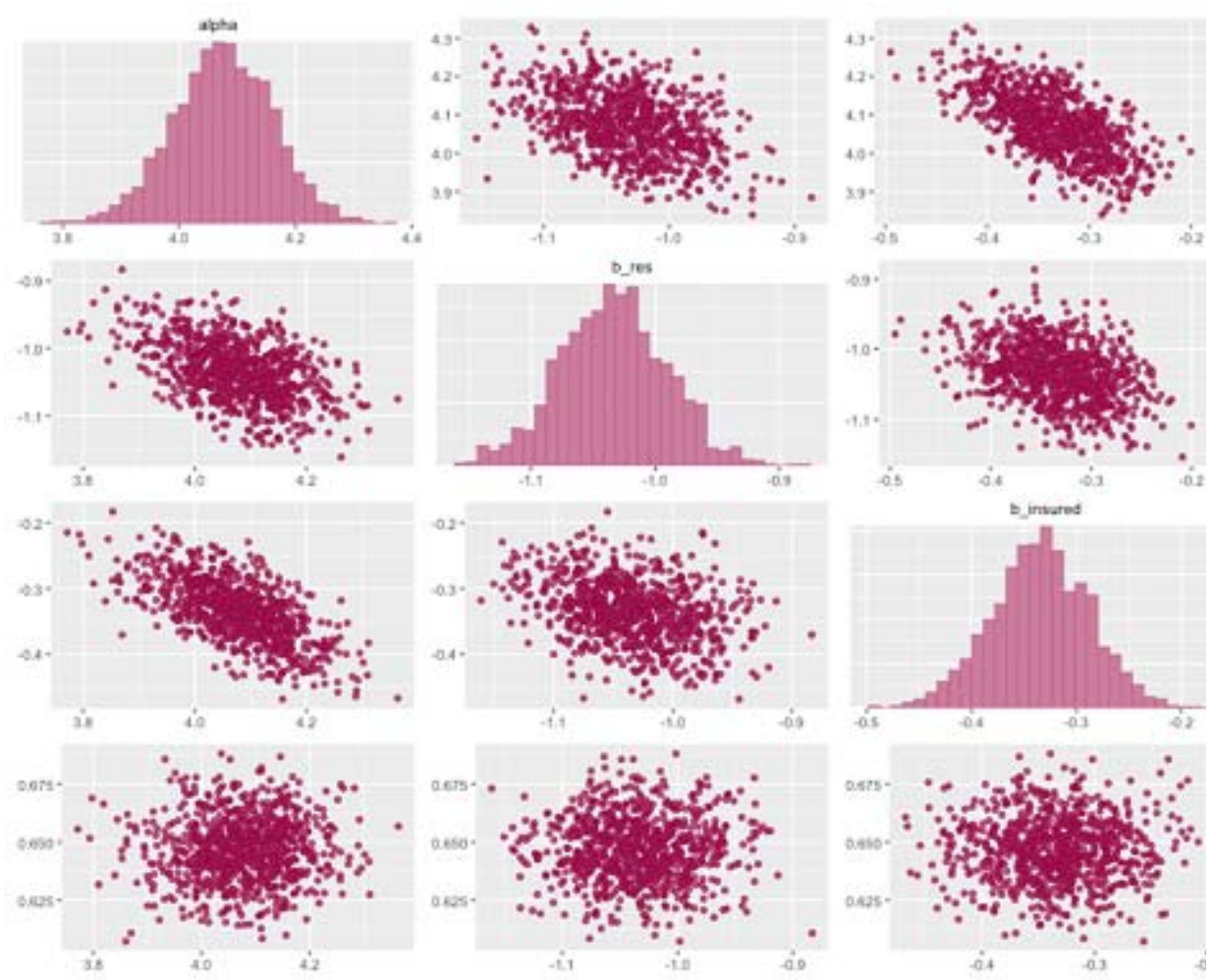

Hình ảnh được sản xuất bởi bayesvl

Theo TS. Vương Quân Hoàng - Giám đốc Trung tâm ISR: "Trong nghiên cứu khoa học, v nghĩa công bố phương pháp khoa học và thuật toán ứng dụng cho các nhà khoa hoc khác việc công bố thông tin khoa học như bài báo khoa học bình thường. Với tính ứng cac khoa học trong tương lai. Chính thức được chấp thuận xuất bản trên CRAN, bayesvl là trường $\mathrm{R}$ rất thông dụng giúp các nhà $\mathrm{KHXHNV}$ sử dụng một cách dễ dàng, gia cố sức mẹ trong thời đại công nghệ 4.0".

Áp dụng vào thực tế, năm 2018, nhóm nghiên cứu của trung tâm ISR đã sử dụng thống được xuất bản trên tạp chí Palgrave Communications thuộc Nature Research (tháng 'bayesvl' tiếp tục được sử dụng trong Preprint về tiếp biến văn hóa (arXiv: https://arxiv.org! của Trung tâm ISR trên tạp chí Data [ESCI; Scopus].

Đối với KHXH Việt Nam và có thể là cả châu Á, hiện nay việc đóng góp phương pháp luận bayesvl với tính sư phạm trong áp dụng phương pháp thống kê Bayesian là đóng góp qua học thế giới, nhất là khi thống kê Bayesian đang được giới khoa học quốc tế quan tâm.

\section{Tài liệu tham khảo:}

Vuong QH, La VP. (2019). BayesVL package for Bayesian statistical analyses in R. Gi DOI:10.31219/osf.io/ya9u6.

La VP \& Vuong QH. (2019). bayesvl: Visually Learning the Graphical Structure of halyesial The Comprehensive R Archive Network (CRAN): <https://cran.r-project.org/web/packages/ 


\section{GIÁO DỤC}

KHOA HỌC - CÔNG NGHẸ

ĐƠN V!̣ TRỰC THUỘC

THÔNG TIN

\section{TRƯÒNG ĐẠI HỌC PHENIKAA}

P Phường Yên Nghĩa - Quận Hà Đông - Hà Nội

C $\underline{024.62918118}$ | Hotline: $\underline{094.651 .1010}$

$\square$ Info@phenikaa-uni.edu.vn

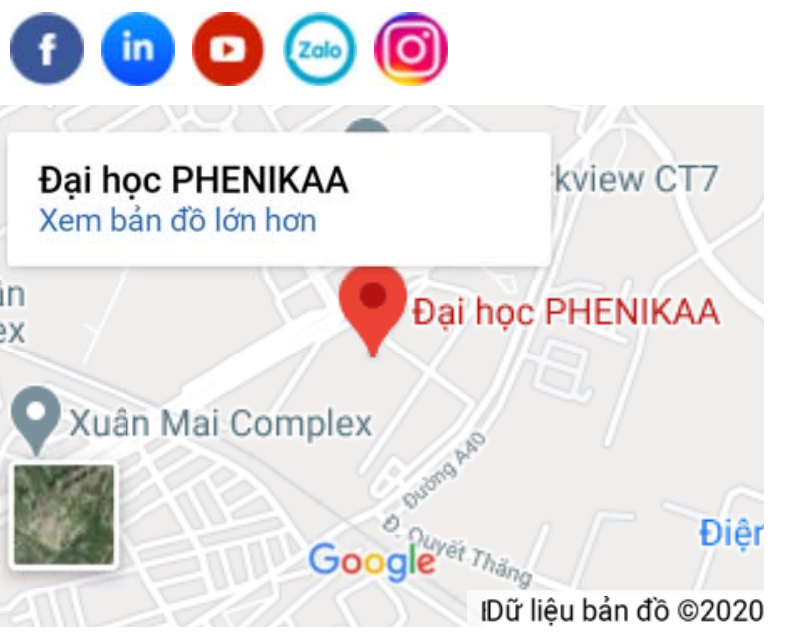

Copyright @ 2018 Trường Đại học PHENIKA^ 